\title{
Study Regarding the Elastic Impression Biomaterials Dimensional Stability
}

\begin{abstract}
CARMEN SAVIN, MAGDA-ECATERINA ANTOHE*, ADRIANA BALAN, ANA SIRGHE, LAURA GAVRILA
Grigore T. Popa University of Medicine and Pharmacy, Faculty of Dental Medicine, 16 Universitatii Str., 700115, Iasi, Romania

In order to have an accurate impression, dimensional modifications must be under control throughout the impression stages, considering they are highly influenced by the variability level during polymerization. The factors with an influence on dimensional stability are:impression material width, tensile modulus, temperature during the imprinting process, storage humidity, the time lapse between imprinting and casting. The study focuses on dimensional modifications of varied elastic impression materials, considering both testing and impression techniques are done in similar conditions in order to assess accurately the behaviour of varied impression materials.Material and methods:The study was based on a laboratory simulation of a clinical situation. There were used two 6-year maxillary molars in the position they have in the oral cavity. A $3 \mathrm{~mm}$ wax layer was added during the next stage its width being checked with an Ivoclar mechanical vernier. The surface parallelism was subsequently checked using a parallelograph and there was taken an individual tray made of photopolymer acrylic. The measurements of this study were limited to the linear dimension, being observed the changes occurred in one direction, although contraction is a volumetric modification. The statistic assessment of the measurement data obtained in the case of the same type of addition silicon materials recorded an increase of the volumetric contraction type in dry environment and in longer time intervals.The addition materials were significantly superior in terms of contraction time, as compared to the previous case, granting higher accuracy to the end product. The Silagum Light presented an increased volumetric contraction in moist environment, the contraction being more significant in longer time intervals. The Xantopren L blue material has a reduced deformation gradient in less than $48 \mathrm{~h}$.
\end{abstract}

Keywords: elastic impression biomaterials, dimensional stability, biomechanic behaviour, fixed prostheses

The territory of fixed restorations anchored in the nonmetallic register or bridged bridges, therapeutic approaches of choice for clinical situations requiring such therapeutic variants in the case of adolescents or young patients, as well as the different types of space maintainers are dependent for their final stage achievement of importance in the clinical-technological algorithm, respectively impression [1, 2]. The biomaterials involved and their biomechanical behaviour have a defining role in the final accuracy of the restoration. Elastic impression materials have now the largest extent of impression materials. Their properties differ considerably depending on the chemical nature, each category presenting advantages and disadvantages, hence the need to know the properties of these materials, so that they can be used differently according to the particular clinical situation and the working technique.In the last decade, the basis of the optical impression was an embodiment that excludes the use of impression materials. Due to high costs, this process is not widely used, and the study of fingerprints is still necessary [3-5]. The dimensional stability of impression is one of the variables that contribute to the accuracy or inaccuracy of dental prostheses, with other factors involved in the changes occurring during the preparation of the impression material and the impression techniques. In order to obtain a true impression, these dimensional changes must be controlled throughout all stages, depending largely on the degree of variability during the polymerization. Impression materials must fulfill certain conditions imposed by the fingerprinting techniques used, as well as the particularities of the prosthetic field. Essential conditions are plasticity, fidelity, elasticity and mechanical strength, dimensional stability, socket time and compatibility with model making materials.In addition to the essential conditions listed above, which ensure a fair footprint, there is a number of secondary conditions that fingerprints must fulfill: pleasant smell and taste, the absence of irritating or toxic components, the longest possible storage, the possibility of using without requiring complicated equipment, the removal of prosthetic field without cost, low cost [6-9].

No impression material fulfills all the conditions of an ideal product. The dentist must choose the appropriate material depending on the clinical situation and the working technique used. This choice can only be made right after detailed knowledge of the properties of the imprinting materials, which determines their performance [10-14].

Dentists are interested, when choosing impression material, more of its physical state during the final, irreversible phase.In the evolution of impression, several periods were distinguished: the period of lack of impressions and materials when the prostheses were carved, the initial period (the wax impression), the period of the rigid and semirigid materials, the period of the elastic materials.Without being mutually exclusive, materials from different periods coexist, being used today. Although rigid materials record accurately all the details of the prosthetic fields, the fingerprints have a great dimensional stability, removing them from the oral cavity without fracturing is almost impossible [15-17].

\section{Experimental part}

Considering the diversity of elastic impression materials used in prosthetics, the research aimed at the comparative assessment of the dimensional change in the dry versus wet environment, reiterating the situations commonly encountered in the dental practice,from the point of view of the proper time for recording the the fingerprint and its subsequent circuit. For this study, a clinical situation was simulated in the laboratory, placing two maxillary six-year

\footnotetext{
*email; magda.antohe@yahoo.com
} 
molars in the position they had in the oral cavity, after which an individual photopolymerizable acrylate film was made. The following materials were used as impression: alginate, Silagum Light admixtures silicones, Xantopren L blue and Impregum soft.

Impressions were made at $37^{\circ} \mathrm{C}$ and under $100 \%$ humidity conditions and cast in 4th grade gypsum at different times and under different storage conditions. The measurements were recorded with a DIGIMATIC digital micrometer, making 3 measurements per cast (figs. 1 and 2).
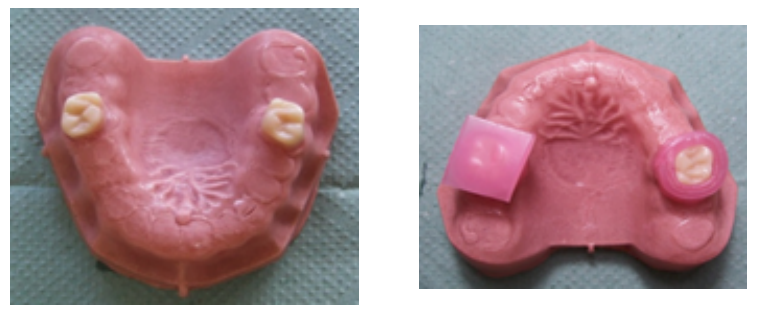

Fig. 1. Aspects of cast preparation for experimental study
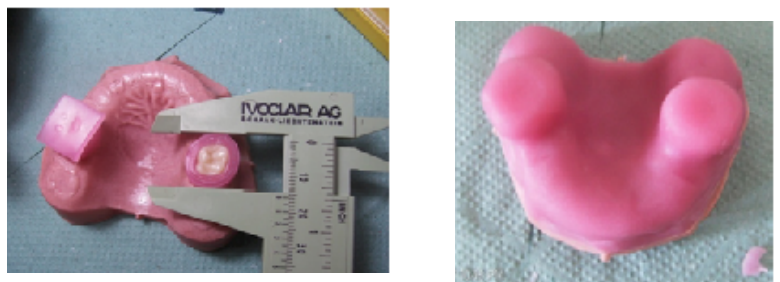

Fig. 2. Aspects of vernier measurements and model preparation before obtaining the individual tray

This study focuses on the dimensional changes of different elastic fingerprint materials, both testing and fingerprinting under similar conditions, which is a determining factor in accurately assessing the behavior of different types of impression materials. Taking into account that their properties differ considerably depending on the chemical nature, each category having advantages and disadvantages, it is necessary to know the properties of these materials so that they can be used differently according to the particular clinical situation and the working technique.For this study, a clinical situation was simulated in the laboratory, placing two six-year maxillary molars in the position they have in the oral cavity .In the next step, a $3 \mathrm{~mm}$ thick wax layer was applied to the teeth, verified with the help of the Ivoclar mechanical caliper. The parallelism of all surfaces was then checked by means of the parallelogram after which an individual photopolymerizable acrylate was made.

\section{Result and discussions}

In order to underline a number of shortcomings due to the lack of some plastic materials, impressions techniques were imagined in two or more paces, for example, vestibular keyprints. The elastic materials are of great structural diversity and have the following characteristics: In the final phase of the socket they have an elastic consistency, The intermediate phase of the socket is relatively short, Fidelity varies widely, decreasing with increasing resistance. The impression maneuvers of these materials are made only in the plastic phase. The partially reversible intermediate phase, in which deformable, irreversible and elastic phase components deform, forces an absolute immobilisation of the fingerprint on the prosthetic field.In the oral environment, materials are subject to a continuous process of degradation by physicochemical attacks, but also due to mechanical pressures exerted on them. The requests may be mechanical (occlusal pressures), with high butintermittent, or bacterial values with permanent effects. Both pressures contribute to the aging of dental material; alloys change their colour tones due to corrosion, and resins due to liquid infiltration and microbial acid attack. They can generate physiological and locally irreversible toxic phenomena .Ideal dental material for use in the oral environment should be as harmful as possible to dental pulp and soft tissues, not to contain toxic substances that are diffusible in the general circulation, to contain no allergenic potential and not to present immediately or in time a carcinogenic effect. All materials used in the oral environment, before being placed on the market, are rigorously assessed through biocompatibility tests. Elastic impression materials distinguish two categories: Hydrocolloids that can be reversible or irreversible and synthetic elastomers which are: silicones, polysulfides and polyethers [18-20].

Subsequent to the statistical processing of the data resulting from the measurements made on the same model model for the silicone additive materials we notice an increase of the type of volumetric contraction in proportion to the number of hours and the dry environment.

As far as the addition materials are concerned, there is some superiority in terms of shrinkage times, which is much lower than in the previous case, giving a certain accuracy to the final model.As for Silagum Light, there is an increase in the volumetric contraction for the wet environment, the higher the time the more the contraction is (fig. 3).

Depending on the type of chemical reaction they are obtained, two types of silicone elastomers are distinguished:condensation silicones, addition silicones. For the preparation of medium and medium consistency silicones, the mixture of the two components previously dosed is made by vigorous spatulation for 1 minute on the glass plate or on the waxed paper until a homogeneous paste is obtained in terms of consistency and colour. The material is loaded into syringes for injection into preparations (fluid material) or applied to the film (media consistency) [21].

The preparing time is 1 minute and the working time is 3-5 minutes. For the preparation of viscous and chitonous consistency silicones, depressions are made in the material, where the appropriate number of droplets or the indicated catalyst length is applied and initially mixed with the rigid spatula, then manually agitated for 30-50 s until a homogeneous color is obtained. The use of protective gloves is recommended.

A standard perforation portrait is selected (if no perforations apply an adhesive lacquer or leucoplast strip for internal retention). Apply the silicone to the standard cavity and insert it into the oral cavity before tooth preparation, create $1-2 \mathrm{~mm}$ silicone fluid space by cutting, and insert 1/3 of the silicone fluid into the syringe and inject around the preparations. The remainder of the fluid silicone fluid is applied to the cartridge over the paste and reinserted the prosthesis on the prosthetic field, where it is maintained by moderate pressure.

It is recommended to use impression with addition silicones when it comes to obtaining particularlyate models in high precision technologies (inlays, adhesive bridges).

Condensation silicones have the largest changes, their contraction being the result of evaporation of secondary volatile products and rearrangement of the bonds formed by the polymerization,Xantopren $\mathrm{L}$ blue being the first one (fig. 4).

Regarding the type of Impregum soft material at room temperature, deformations were observed much lower than in the wet environment (fig. 5). 

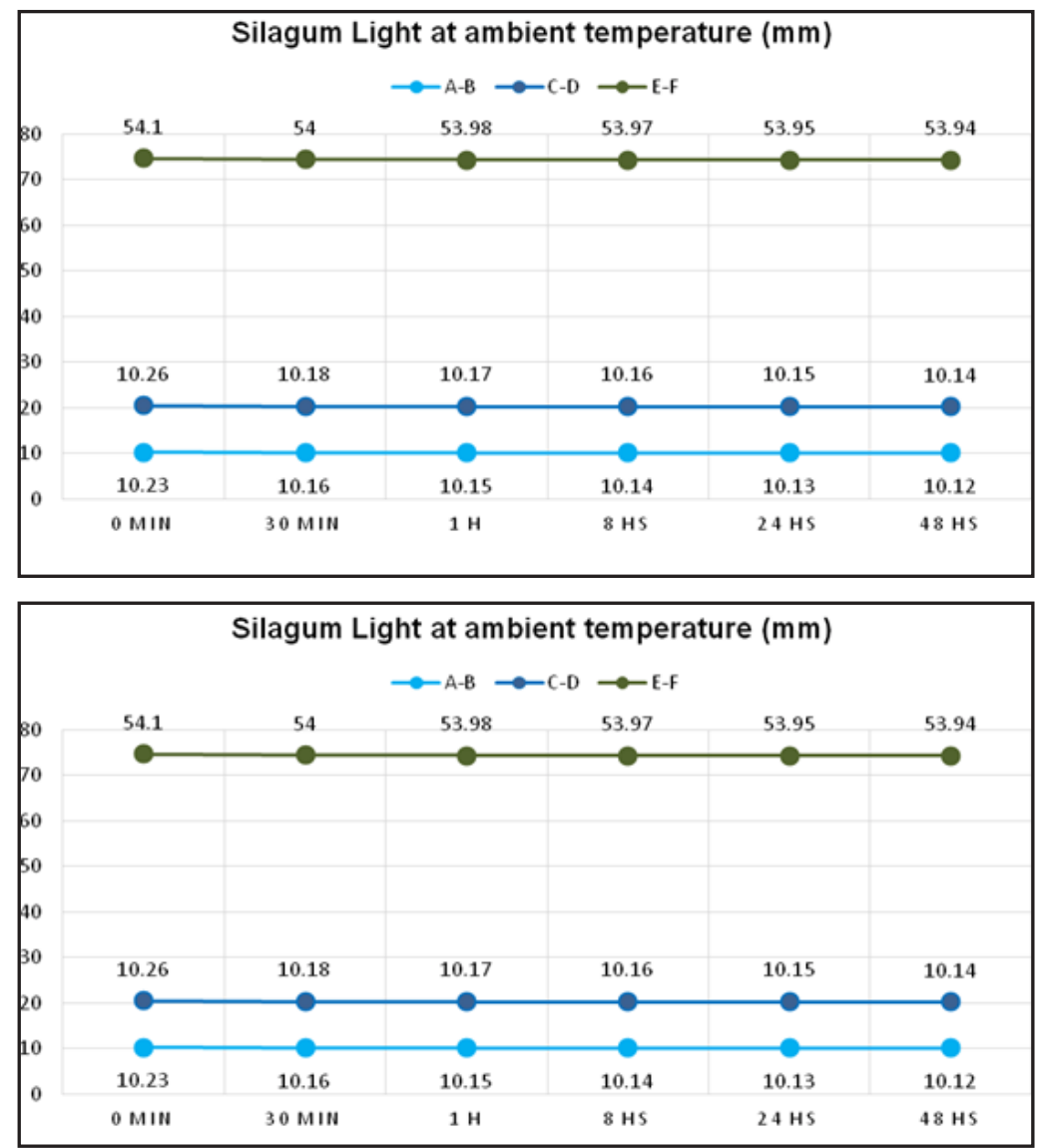

Fig. 3. Aspects of dimensional changes in dry and wet environment for Silagum Light
The smallest deformations were recorded on polyether materials by automatic kneading.

Polyethers are presented in three consistencies: viscous, average, fluid. The two amounts of base paste and catalyst expressed on waxed paper or on the glass plate are mixed by vigorous spattering until colour homogenization, the preparing time being 35-50 s. Appropriately prepared material is applied, depending on the consistency, in the syringe or in the individual porthole provided with stops. The double-mixture technique or the two-stroke technique is used, with the hardening time being 5-6 min. Once theimpression maneuvers have been completed, it is forbiden to retain the print in water (the material is hydrophilic). Immediate casting of the model is recommended.

The dimensional stability of impression fingerprints is one of the variables that contribute to the accuracy or inaccuracy of dentures. Other factors involved include the changes that occurred during the preparation of fingerprint material as well as fingerprinting techniques. In order to
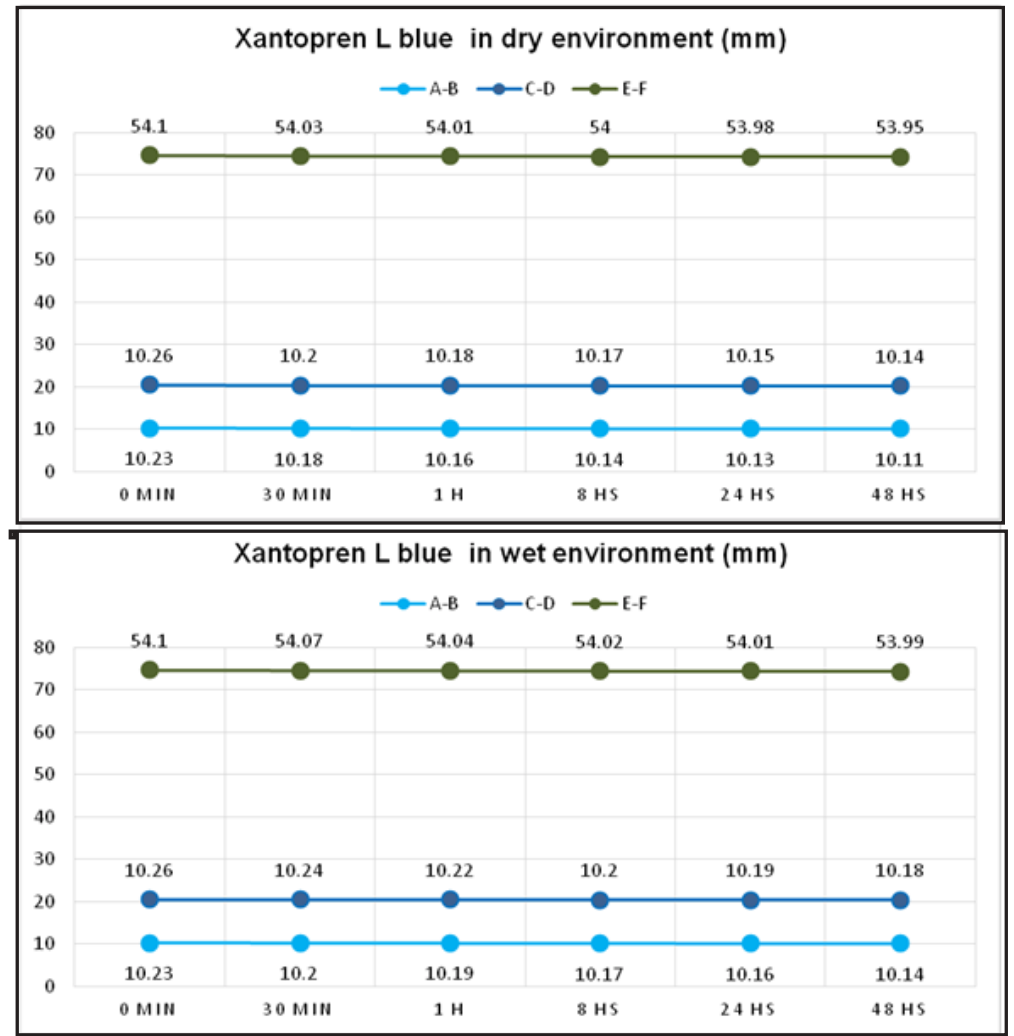

REV.CHIM. (Bucharest) $70 \diamond$ No. $3 \diamond 2019$
Fig. 4. Aspects of dimensional changes in dry and wet environment for Xantopren $L$ blue 

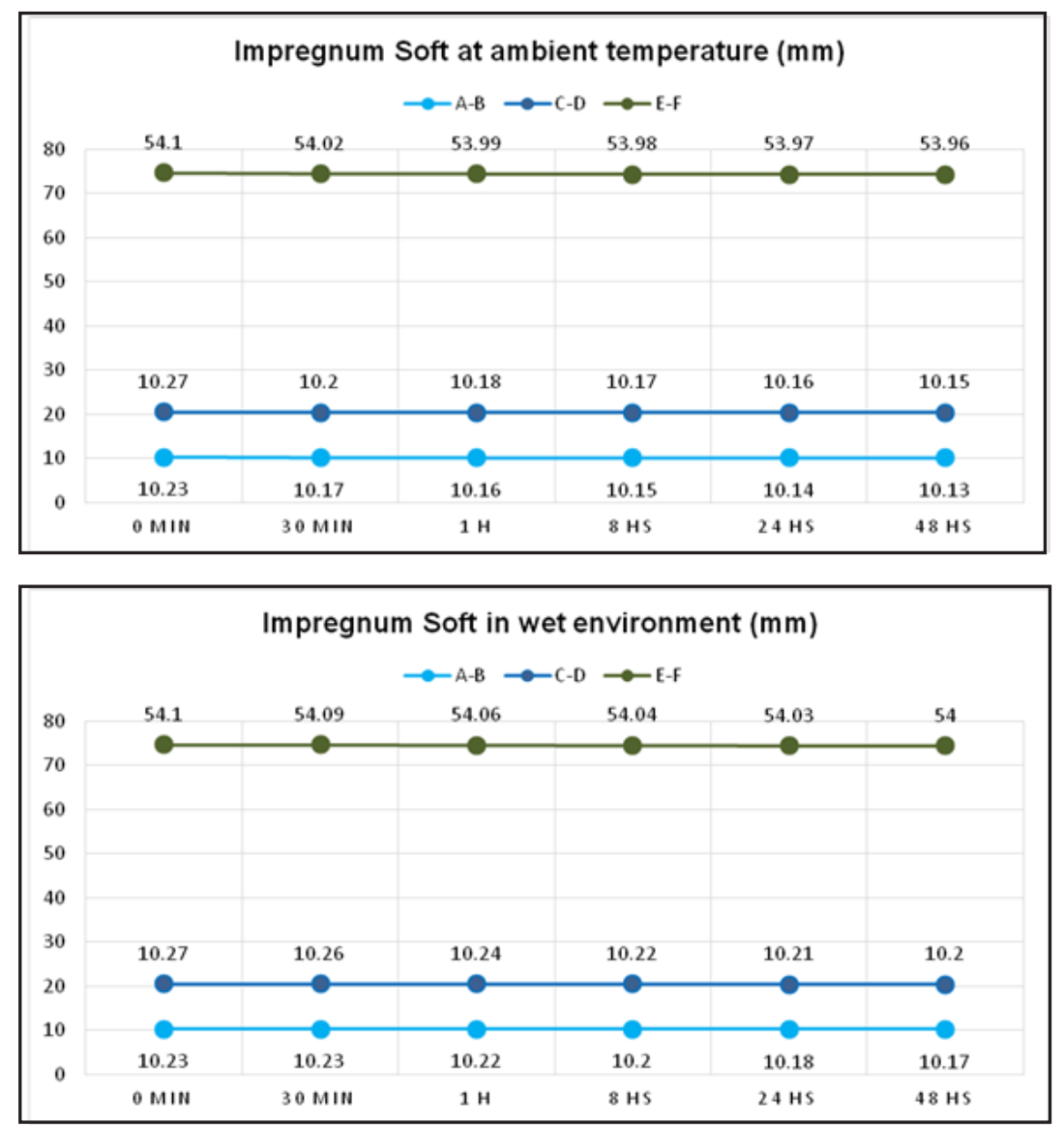

Fig. 5. Aspects of dimensional changes in dry and wet environment for Impregum Soft obtain a true impression, these dimensional changes must be controlled throughout all stages, depending largely on the degree of variability during the polymerization.

Addition silicones have the smallest dimensional changes, followed by polyethers and polysulphides which have lead dioxid and copper hydroxide accelerators. The contraction rate of the elastic impression materials is not uniform throughout the first $24 \mathrm{~h}$ after removal from the oral cavity, with approximately half of the contraction recorded on the first day occurring in the first hour. Some silicone impression release hydrogen after tapping, and therefore the models should not be cast in the first 1-2 $\mathrm{h}$.

\section{Conclusions}

Based on the results obtained, the following conclusions can be drawn:

-Condensation silicones have the largest changes, their contraction being the result of evaporation of secondary volatile products and rearrangement of the bonds formed by the polymerization, Xantopren L blue being the first one.

-Addition silicones have the smallest dimensional changes, followed by polyethers and polysulphides which have lead accelerators and copper hydroxide.

-The contraction rate of the elastic fingerprint materials is not uniform during the first $24 \mathrm{~h}$ after removal from the oral cavity.

\section{References}

1.FORNA, N., Proteticã Dentarã, Ed. Enciclopedica, Bucuresti, 2011, p. 96.

2.RIZKALLA, A.S., JONES, D.W., Dent. Mater., 20, no. 2, 2004, p. 207. 3.ELLIS, J.S., PELEKIS, N.D., THOMANSON, J.M., J. Prosthodontic, 16, 2007, p. 37.

4. CRAIG, R.G., Restaurative dental biomaterials, Ed. All Educational, 2001, p. 395
5.TATARU, C., FORNA AGOP, D., FORNA, C. N., Romanian Journal of Oral Rehabilitation, 8, no. 3, 2016, p.120.

6.CALIN, A., FORNA AGOP, D., FORNA, C.N., Romanian J ournal of Oral Rehabilitation, 8, no. 3, 2016, p. 111.

7. AMINOV, L., VATAMAN, M., MAXIM, D.C., SALCEANU, M., SURLIN, P., CHECHERITA, L.E., Mat. Plast., 51, no. 3, 2014, p. 246.

8. VOICU, G., HADANOIU, A.I., ANDRONESCU, E., BLEOTU, C., Rev. Chim. (Bucharest), 63, no. 10, 2012, p.1031.

9. ZAHARIA, C., VASILE, E., GALATEANU, B., BUNEA, M.C., CASARICA, A., STANESCU, P.O., Mat. Plast., 51, no. 1, 2014, p. 1.

10. SIMION, D., GAIDAU, C., NICULESCU, M., SIMION, M., Mat. Plast., 50, no. 4, 2013, p. 323.

11.CARDIFF, R.D., BOROWSKY, A.D., The Journal of Clinical Investigation, 124, no.2, 2014, p. 478.

12.BARTOK F.L., FORNA N.C., Romanian Journal of Oral Rehabilitation, 67, no. 9, 2016, p. 1722.

13.MANAILA, E, NICULESCU, M.D, STELESCU, M.D., Rev. Chim. (Bucharest), 66, no. 8, 2015, p. 1193.

14.RATNER, B.D., HOFFMAN, A.S., SCHOEN, F.J ., LEMONS, J.E., Biomaterials Science: An Introduction to Materials in Medicine. 3rd edition. Elsevier Inc. 2013, p.82.

15. WASSELL RW, BARKER D, WALLS AW., Br. Dent. J., 192, no.12, 2002, p. 679.

16.SAMET N, SHOHAT M, LIVNY A, WEISS El., J. Prosthet. Dent., 94, no.2, 2005, p. 112.

17.SINESCU, C, TIMOFTE, C., STAN, A.T, COJ OCARIU, A.C, EREMIA, C.,FREIMAN, P.C, MILADINOV, M, NEGRUIU, M.L, STRATUL, I., ReV. Chim. (Bucharest), 65, no. 8, 2015, p. 985

18.ROSENSTIEL S, LAND F, FUJIMOTO J., Contemporany Fixed Prosthodontics 5th edition, Elsevier Inc. St. Louis 2016. pp. 367-381. 19.RAVIKUMAR CM, SANGUR R., Indian J . Dent. Res., 23, 2012, p. 209. 20.BELEI, D., FORNA, N.C., SANDU, I., BIRSA, M.L., Rev. Chim. (Bucharest), 65, no. 1, 2014, p. 80.

21.NICULESCU, O., NICA, P., GURLUI, S., Mat.Plast., 46, no. 3, 2009, p. 336.

Manuscript received: 17.09 .2018 